Article

\title{
Evaluation System for the Implementation of Public Passenger Transport as a Public Service Obligation
}

\author{
Janez Blaž ${ }^{1, *}$, Klemen Zajc ${ }^{2}$, Samo Zupan ${ }^{3}$ and Miha Ambrož ${ }^{3}$ \\ 1 Ministry of Infrastructure, SI-1000 Ljubljana, Slovenia \\ 2 Independent Researcher, SI-1234 Mengeš, Slovenia; zajc.klemen@gmail.com \\ 3 Faculty of Mechanical Engineering, University of Ljubljana, SI-1000 Ljubljana, Slovenia; \\ samo.zupan@fs.uni-lj.si (S.Z.); miha.ambroz@fs.uni-lj.si (M.A.) \\ * Correspondence: janez.blaz@gov.si
}

Received: 8 May 2019; Accepted: 12 June 2019; Published: 14 June 2019

\begin{abstract}
The research in this article relates to an evaluation system for the implementation of lines in a public passenger transport system as a public service obligation. The purpose of this research is to present the methodology for the performance evaluation of a public passenger transport system that serves the public transport authority as a tool for making further decisions. The procedures first refer to the experimental determination of the criteria and then perform the first evaluation in the form of the value of the objective function. This is followed by multi-stage linear regression and optimization procedures that give the relation between the dependent variable $(\mathrm{Y})$ and the independent variables $(X$,$) that is, the criteria. Optimization is carried out in the coefficients (\beta)$, which are excluded from the optimization procedures in the case of the calculated statistical degree of insignificance. This research also shows procedures for changing the mathematical form of the criteria records and determining the impact on the final result of optimizations.
\end{abstract}

Keywords: public passenger transport; public service obligation; linear regression; optimization

\section{Introduction}

The subject of research in this article relates to the problem of the optimal implementation of public passenger transport as a public service obligation (PSO_PPT). This also means that public passenger transport (PPT) must also be carried out in areas where revenues cannot cover the full costs, resulting in the need for additional subsidies and co-financing [1-6]. Articles 4 and 5 in [1] refer to the system of selecting public service providers and the mandatory content of contractual relations in the event of the performance of compulsory public service. Directorate-General Mobility and Transport of the EU [2] highlights the political initiatives of the European Commission, which should help the transport sector to become more sustainable and innovative, and remain competitive in a changing global environment. Problems relating to infrastructure, digitalization, information, and the protection of passenger rights are described in [3]. In this regard, this study lists the four main legal gaps (grey zones) that are not covered by European regulations. Velde et al. [4] describe the issue of competitive tendering procedures, the differences between net and gross contracts, and the role of the public transport authority in the Netherlands. Mouwen and Ommeren [5] describe the effect of the competitive tendering of public transport costs, subsidies, and ridership. A model of operational costs, subsidy, and passenger kilometers is also presented. Suggestions are made regarding the size of the geographical areas of the concession areas. Farsi et al. [6] refers to the cost structure of Swiss multi-modal urban transport operators in order to achieve economies of scale.

At the same time, the European Union also encourages transport companies to use environmentally friendly and sustainable vehicles [7-9]. In [7], three priority areas related to the European low emission 
mobility strategy are presented: Increasing the efficiency of the transport system, speeding up the deployment of low-emission alternative energy for transport, and moving towards zero-emission vehicles. Communication from the Commission to the European Parliament, the council, and the European economic and social committee of the regions [8] presents a strategy for low-emission mobility as well as EU-wide standards created in co-operation with EU Member States, the industry, and the European Standardization Organizations. The author of [9] highlights the specificity of public passenger transport organizations in each country or local environment; such organizations need to be tailor-designed to these specific characteristics.

A critical role in this system is assigned to the public transport management, that is, the public transport authority (PTA), which is responsible for establishing the organizational structure, executing the system of operational implementation and controls, financing the system, and optimizing the implementation of PPTs in relation to available public funds. There are various organizational forms of public passenger transport management and the method of concluding concession contracts. The literature [4] also presents an example of the procedures for selecting the best contractors, as well as the differences between net and gross concession contracts. Also, in the literature [5] are presented the procedures and effects of the selection of the most favorable PSO_PPT providers on the basis of public tenders. Some comparative analyses between public transport authorities are presented in the literature [10]. The effectiveness of public passenger transport depends on a number of factors, such as the available technologies, set political priorities and objectives, planning processes, and the implementation of controls [11]. In this literature, an overview of the optimization approaches in this area is derived, based on strategic, tactical, and operational levels. For each of the studies resulting from the literature, there are authors, objectives, constraints of the system, solution methods, and cases. Thus, among the described constraints of the system, the following are indicated: Line length, trip length, demand satisfaction, number of lines, maximum travel time, minimum travel time, percentage of passengers using $\mathrm{n}$ transfers, vehicle capacity, passenger arrival rates, deviation from a timetable, etc. Public passenger transport complexes are shown in the literature [2-5], in which the approach through spatial infrastructure analyses is presented to prevent traffic congestion and achieve sustainable development [12]. In the literature, a bus network optimization model is presented, in which the network topology parameter is set as the objective with the constraints (line length, the no -linear coefficient of line, station capacity, the density of the transportation network, the average transfer coefficient, etc.).

When describing organizational processes, it follows from the manager's task that, in advance, for the new period of PPT implementation, it is necessary to anticipate and determine the scope of works and the content of new contracts in public passenger transport (Figure 1). In the next phase, public transport operators (service providers) prepare tender offer documentation in which they determine tender timetables, cost elements, and other data relating to vehicles, drivers, and other elements. In the next phase, with the participation of transport operators and the PTA, a program for the implementation of the PSO_PPT is prepared, which is the basis for the preparation of a national timetable. This is followed by the signing of concession contracts for a new period, the implementation of the PSO_PPT in accordance with the new contractual provisions, and the reporting of results. The existing system is based on the implementation of lines according to the prescribed timetable, consisting of a sequence of the itineraries, the distance between stations, time intervals, and departure times. The existing 26 transport operators take care of the collection of public passenger transport needs and suggest changes in this regard. The goal is to transfer the processes of planning, analyzing user needs, evaluating results, and optimizing, to a large extent, to the PTA. As part of the further development of this field, we established an infrastructure model consisting of station points and line sections, as shown in Figure 2 (phase 1 of the research) and Figure 3. In the continuation of the research, we proceeded to the research that is the subject of this article (Figure 2, phase 2 of the research). 


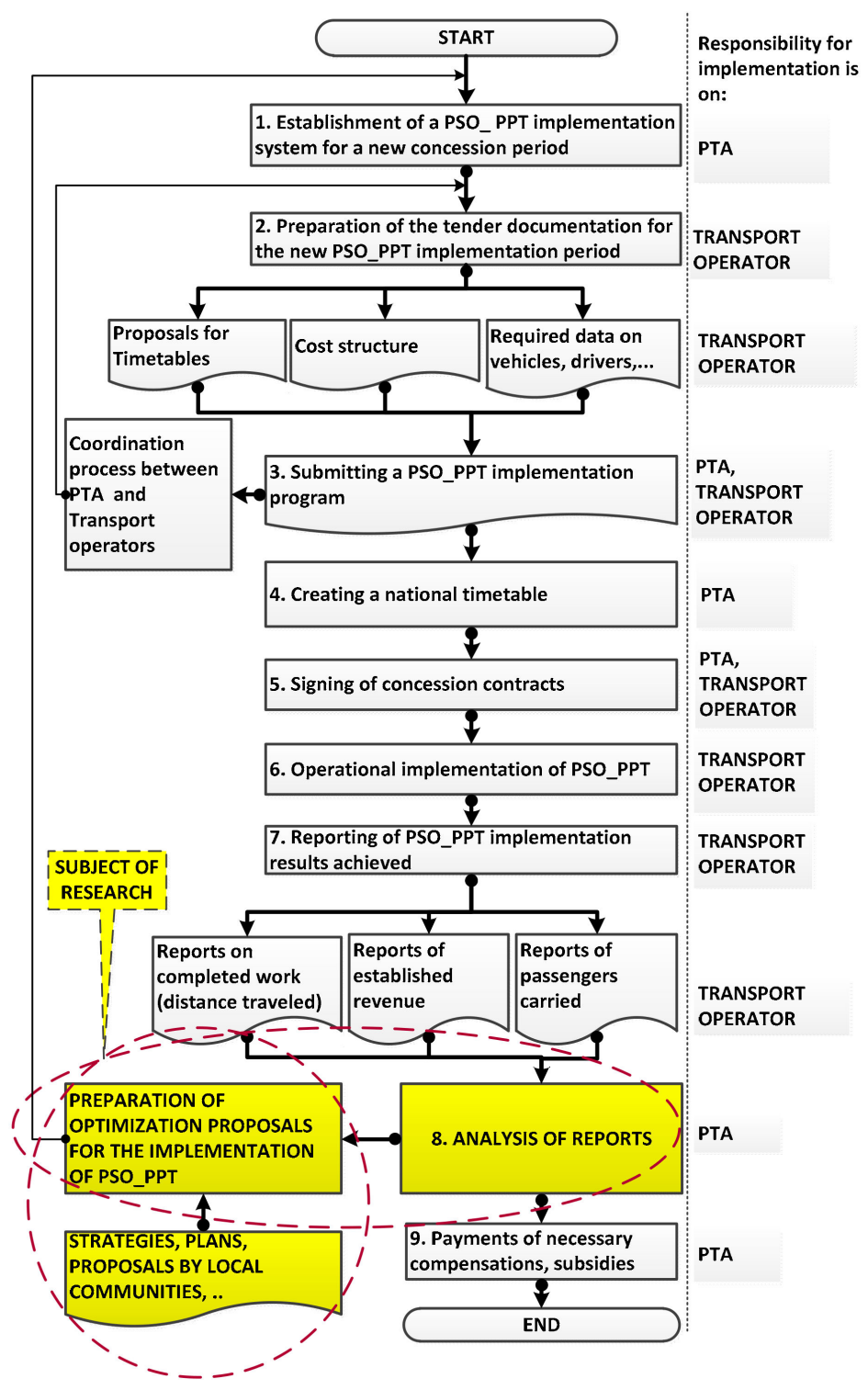

Figure 1. Activities and processes of the PTA in the PSO_PPT system.

The PSO_PPT implementation reports consist of three main groups:

- Reports on the completed work (number of passengers carried, the number of kilometers traveled, the number of tickets sold, etc.).

- $\quad$ Reports on revenue from the sale of tickets and revenues from subsidies.

- Cost reports, depending on the fleet used, number of drivers, and other costs.

Research in this article relates to the optimization processes and evaluations that are the result of the described processes. The goal was set to establish a methodology for assessing the effectiveness of such a PSO_PPT implementation, as well as benchmarking the implementation of individual lines. In addition, we are interested in what measures can increase the efficiency of the system (individual lines) of PSO_PPT [6,13-15].

\section{Materials and Methods}

In the described research, we used the methodology, as shown in Figure 2, which consisted of two phases. The importance of setting up an infrastructure basis for further research on public transport optimization is presented in the literature [16]. 


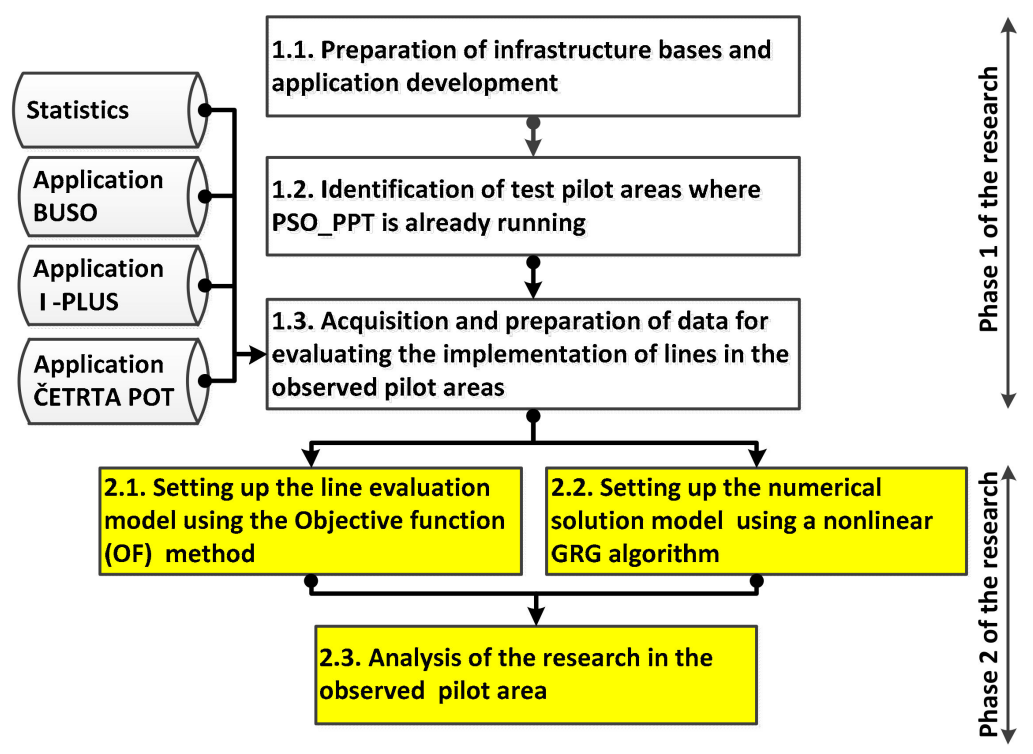

Figure 2. Methodology of the presented research.

It is important that bus line sections are precisely defined through itineraries, in which public passenger transport lines take place, as shown in Figure 3. This is the basis for setting kilometer distances and driving times between the station points, taking into account the direction of travel (journey) along a certain itinerary on the line. Also, based on this, calculations of the costs of the PSO_PPT implementation, as well as the rates of fares, are determined [17].

Phase 1 is the establishment of the necessary infrastructure base, the selection of the pilot area, and the acquisition of all the data needed for further research and procedures. In the preparation of infrastructure databases, an analysis of the layout of line sections that connect individual station points was first done, as described in [18-22]. In the vicinity of each station point, we obtained statistical data on the density and structure of the population in the radius of $500 \mathrm{~m}$ around it. The determination of the pilot area was based on the condition that a sufficiently large representative sample of lines in the PSO_PPT system, covering both profitable and non-profitable lines, should be covered [23]. Among other things, it was also stipulated that the lines should be carried out in both densely populated and sparsely populated (hilly) rural areas. The selected pilot area covering 28 lines in four concession areas (marked as A, B, C, and D) of the PSO_PPT is shown in Figure 4.

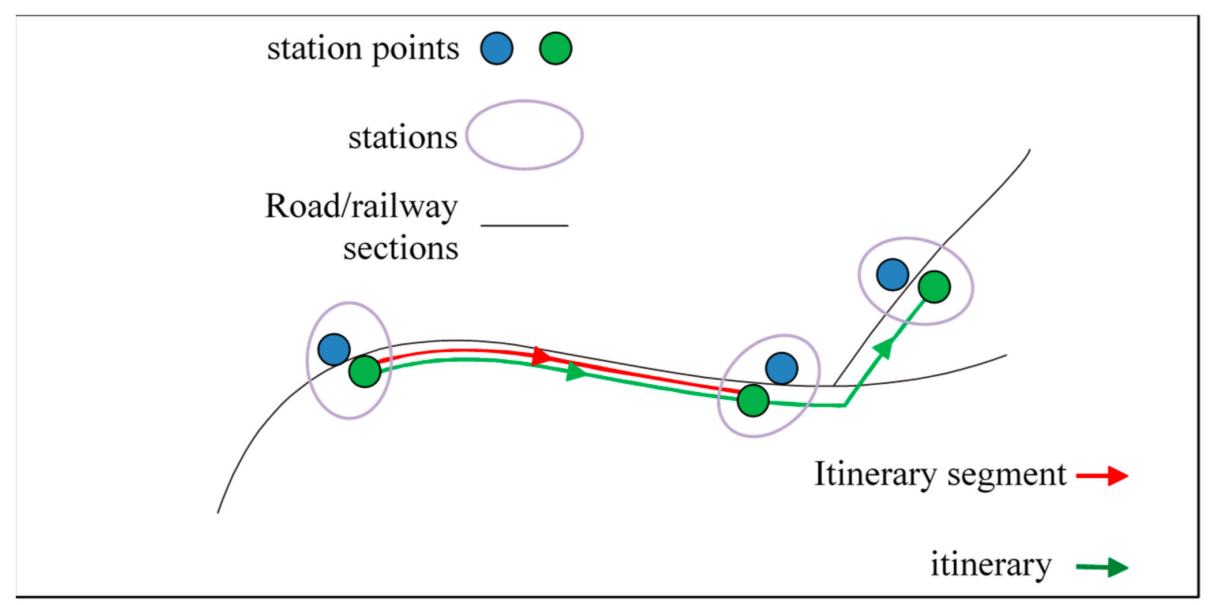

Figure 3. Entities in the public passenger transport infrastructure network (source [19]). 


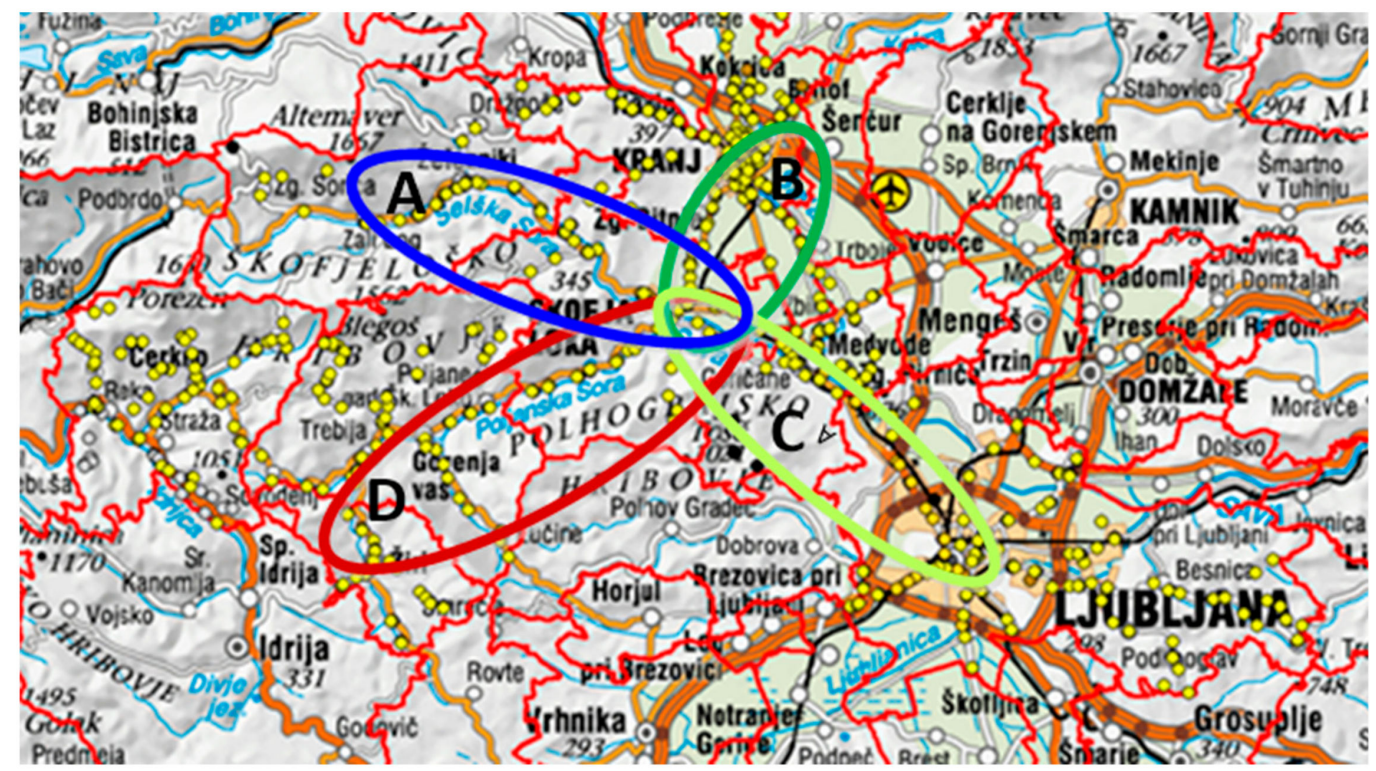

Figure 4. Selected pilot area in the PTA management area with predefined infrastructure basis (source of the map base layer: The Surveying and Mapping Authority of the Republic of Slovenia).

Figure 5 shows 28 lines in four concession areas. In a continuation of the research, we collected data in this selected area from individual bus journeys on these 28 lines according to the valid register, which is managed by the competent PTA. For the purposes of this research, we collected data on these 28 lines on the normal whole working and school day in March 2017. On previously defined infrastructure bases, which include station points and line sections, for each station point, for each line treated, data on the number and structure of the population in the radius of $500 \mathrm{~m}$ were obtained [18]. The times of bus trips were obtained from a valid timetable, and travel times by car were obtained from the Google Maps website for the distance travelled on the bus line itinerary. The links (crossing) of lines at each station point of the observed lines were obtained from the valid timetable register. Measurements of the actual times of travel by bus and deviations from the prescribed ones were carried out on one of the lines under consideration in the pilot region using the application [20].

In determining the price affordability, we proceeded from the existing tariff scale, so that we obtained the costs of the passenger, using a bus for driving on a particular line. For the cost of the car, a simulation of the calculation was made based on the average consumption of diesel fuel (6 liters/100 $\mathrm{km}$ ) and the retail fuel price, when driving a car following the same itinerary on the same line. The number of passengers entering the bus at each station point was obtained through a specially developed application [21]. It is an electronic collection of data on the validations of passengers at entry at each station point and the calculation of the travel matrix of passengers (origin-distance). From the obtained data, we also calculated the number of passengers on the bus (occupancy of the bus).

The pilot area, which is the subject of this research, comprises four typical different characteristic migration flows, which we have labelled as potential concession areas and could be the subject of new tendering concessions (Figure 5). We decided on this pilot region because the migration flows are going to the capital city and also to the sparsely populated (hilly) areas. Therefore, the center of this area was identified as a location (city), marked in Figure 5 as "ŠL".

We set up three models for evaluating the implementation of lines based on pre-set criteria, as shown in Table 1. This table shows all input parameters that were entered in the individual criteria and the selected model. In setting the criteria, we proceeded from the existing experience and knowledge of the problem of the implementation of PSO_PPT. The objective was set to create a tool for validating the implementation of lines for the needs of the PTA, as shown in Figure 1. Therefore, with the described eight criteria, according to our knowledge of the problem, we tried to fully evaluate the implementation of lines. 
When setting up a model for evaluating the implementation of lines, it is first necessary to define the criteria for these evaluations, which we labeled $\left(X_{i}\right)$. These are the criteria that can be measured during the performance of different lines, such as the number of passengers carried, travel times required, price suitability, number of passengers entering the stations, accuracy of the service, line diversions, possibility of the extension of lines, the possibility of transferring to other forms of public transport, and others.

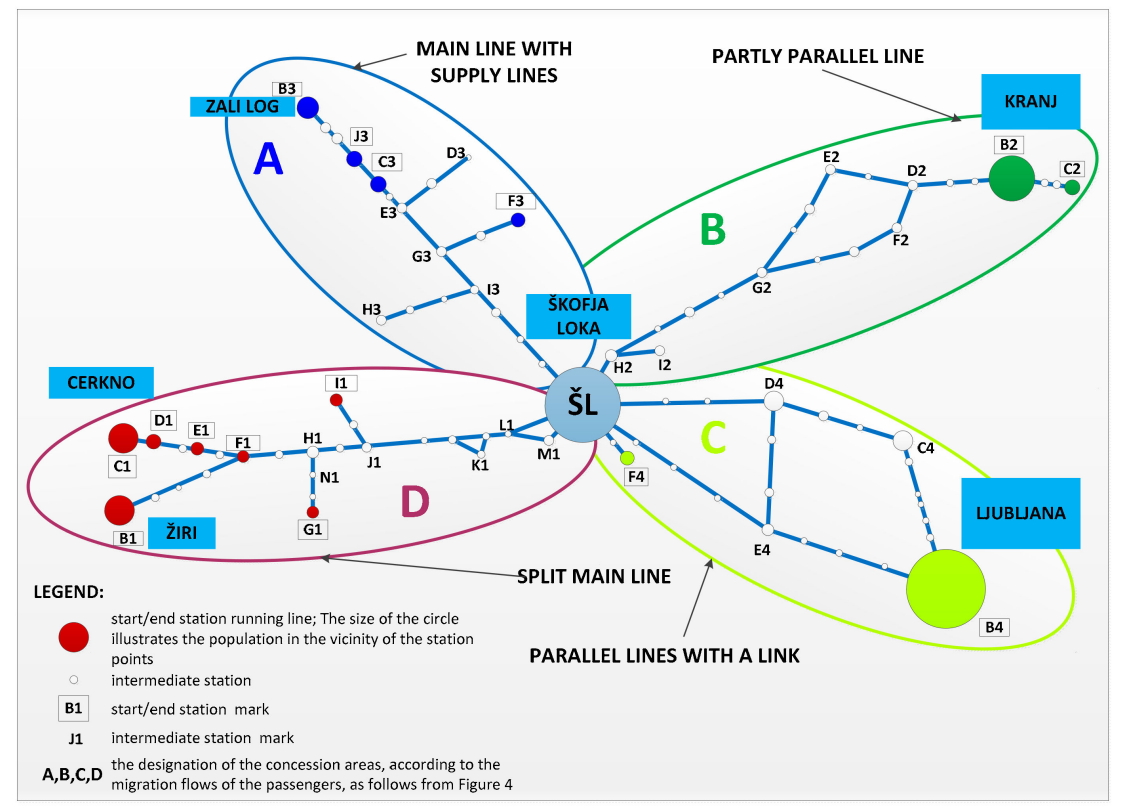

Figure 5. Selected pilot area with 4 concession areas and 28 lines, which is the subject of further research, as follows from Figure 4.

Table 1. Input variables in three models studied according to selected criteria.

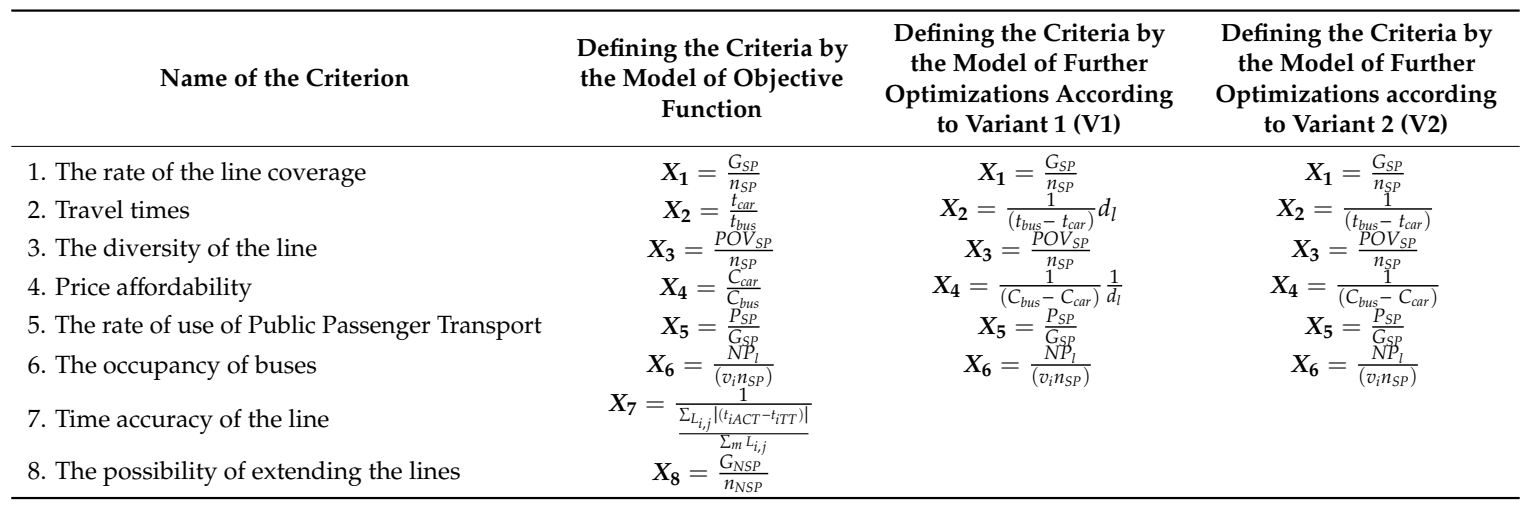

The core of the research in this article was phase 2 (Figure 2) and was based on the collected PSO_PPT implementation data in the selected pilot area, following phase 1 . The goal was to determine the most appropriate model for evaluating the implementation of lines. In doing so, we used previous research [24] that describes optimization methods to characterize bus route designs using some general network measures and traffic indicators using linear regression, where the coefficient optimization was performed. This literature also shows research demonstrating a regression model for assessing the effectiveness of the layout of bus lines and travel times. A student's $t$ distribution was used with a 95\% confidence interval. Also, the research $[25,26]$ describes the research of specific criteria that are important from the point of view of passengers for the use of public passenger transport. In [25], specific criteria are presented that influence the decisions of passengers for the use of public 
passenger transport. It is emphasized that improving these criteria would have a significant impact on incentives for the use of public passenger transport, rather than the use of private cars. In [26], the public assignment model is shown, which is written in the form of a utility function as the sum of the products of the coefficients and criteria.

\subsection{Establishing the Optimization Model}

The purpose of the optimization model was to set up an optimization process, which could be used to evaluate the implementation of lines in the PSO_PPT system. The procedure consisted of two phases, as shown in Figure 2. First, we set up a list of criteria together with a mathematical notation, as shown in Table 1 [27]. In this reference, an example of the selection of criteria for determining the impacts on traffic accessibility and suburban development is presented. The four main criteria and 13 sub-criteria are listed, among which are the travel time, transport costs, tariff system, etc.

In this, "Defining the criteria by the model of objective function" refers to Section 2.1. in Figure 2 and "Defining the criteria by the model of further optimizations according to variant 1 (V1)" and "Defining the criteria by the model of further optimizations according to variant 2 (V2)" refer to Section 2.2. shown in Figure 2. A set of possible input data (variables) acquired from the operational implementation of the PSO_PPT and from which the mathematical notations of the criteria are formed is as follows:

- $\quad$ The number of passengers entering the bus at the station $\left(P_{S P}\right)$.

- The number of passengers on the bus (occupancy of the bus) $\left(N P_{l}\right)$.

- Auto travel times $\left(t_{c a r}\right)$.

- Bus travel times $\left(t_{b u s}\right)$.

- Sum of all links (crossing) of lines at each station point of the observed line (POV $\left.V_{S P}\right)$.

- Cost of using bus transport, calculated as the price of a one-way ticket when driving by bus on the observed line $\left(C_{\text {bus }}\right)$.

- Cost of using a personal car, calculated on the consumption of diesel fuel when driving by car on the observed line $\left(C_{c a r}\right)$.

- Population density in a $500 \mathrm{~m}$ radius around each station point $\left(G_{S P}\right)$.

- Number of bus journeys in the observed time of carrying out measurements in the selected pilot area $\left(v_{i}\right)$.

- Length of lines $\left(d_{l}\right)$.

- Number of station points on the line $\left(n_{S P}\right)$.

- The absolute values of the difference between the actual driving times and driving times as follows from the timetables on the line $\left(\left|\left(t_{i A C T}-t_{i T T}\right)\right|\right)$.

- The performed measurements of the actual run times on the $L_{i}$ driving line on journey $j\left(L_{i, j}\right)$.

- The number of new station points that can be added to the observed line, thereby improving the accessibility standard $\left(n_{N S P}\right)$.

- The cumulative number of inhabitants around the new station points $\left(G_{N S P}\right)$.

- Criterion $\left(q_{\mathrm{j}}\right)$.

- Weights $\left(w_{\mathrm{j}}\right)$.

- $\quad$ Target cost price $\left(C_{c}\right)$.

2.1.1. Methodology for Setting up the Model of the Objective Function

We collected all the necessary data as it follows from the mathematical notation of the individual criteria. In the next phase, we calculated the sum of products: Criteria, correction factors, and weights for each of the lines, $i \in\{1, \ldots 28\}$, and for each criterion, $j \in\{1, \ldots 8\}$, and what we call the objective function (OF). From the viewpoint of the PTA, the line with a higher functional value has a better efficiency: 


$$
O F_{i}=\sum_{i=1}^{28} \sum_{j=1}^{8} X_{i j} \cdot q_{j} \cdot w_{j}
$$

Each of the criteria was also weighted. The weights system shows the magnitude of the influence of the subjective criterion of the importance of each criterion. In these studies, the weighting values were determined from the PTA point of view, but analyses were also made from both the passengers' and from the operators' points of view. The weighting system was normalized in such a way that the weight value for each criterion was between 0 and 1 , and the total sum of the weights in determining the final value of the function in the observed lines was 1 . In determining the value of the weights, we allocated $70 \%$ of the values to the criteria derived from the population surveys on the satisfaction of the users of public passenger transport, which was acquired from computer-based online surveys within the general population [28]. The results of this survey were derived from computer-based online surveys, and the method of random selection of respondents in the sample was used. The sample included $n=1024$ respondents. The research related to the analyses of questionnaires on determining the reasons for the non-use of public passenger transport. In determining the value of the weights of the objective function, we decided to allocate $70 \%$ of the values to the criteria derived from this survey.

Thus, the criteria $\left(X_{1}, X_{3}\right.$, and $\left.X_{8}\right)$ influence the accessibility of PPTs; together, they set $40 \%$ of the value of the weight. We allocated $15 \%$ for time efficiency $\left(X_{2}\right)$ and $15 \%$ for affordability $\left(X_{4}\right)$. Criteria that are important from the point of view of the PTA $\left(X_{5}\right.$ and $\left.X_{6}\right)$ were weighted with a total weight of $30 \%$. Due to technical and financial reasons, the measurements of time accuracy $\left(X_{7}\right)$ were only made on line ŠL_D4_C4_B4, as follows from Figure 5, and we excluded it from further calculations.

To obtain useful values of the function as the sum of all criteria and then to make comparisons of the values, we introduced correction factors $(q)$ to compensate the differences between the different units in the equations. The analysis of the experimentally determined correction factors was supplemented by analysis so that the values of the individual criteria were first normalized at intervals ( 0 to 1$)$ for all 28 lines. This was done by dividing the values of the individual criteria for all 28 lines with the highest value of each criterion. The values obtained were multiplied by the weights, and thus the values of the objective function were obtained. On the basis of comparative analyses, we established the appropriateness of setting the correction factors, as follows from Table 2.

Table 2. The value interval of the individual criteria, the size of the correction factors, and the value of the weight in the calculation of the objective function.

\begin{tabular}{ccccc}
\hline Criteria & Correction Factor $\left(q_{\mathbf{j}}\right)$ & Minimum Value & Maximum Value & $\begin{array}{c}\text { The Size of the } \\
\text { Weight }\left(w_{\mathbf{j}}\right)\end{array}$ \\
\hline$X_{1}$ & $q_{1}=1000$ & 0.04 & 0.80 & 0.20 \\
$X_{2}$ & $q_{2}=10$ & 0.47 & 1.38 & 0.15 \\
$X_{3}$ & $q_{3}=10$ & 0.02 & 0.40 & 0.10 \\
$X_{4}$ & $q_{4}=10$ & 0.46 & 0.89 & 0.15 \\
$X_{5}$ & $q_{5}=1000$ & 0.03 & 2.12 & 0.15 \\
$X_{6}$ & $q_{6}=10$ & 0.03 & 0.78 & 0.15 \\
$X_{7}$ & $q_{7}=1000$ & 0.00 & 0.03 & 0.00 \\
$X_{8}$ & $q_{8}=10$ & 0.00 & 0.50 & 0.10 \\
\hline
\end{tabular}

To determine the degree of independence between individual criteria, we calculated the correlations. Table 3 shows the correlation matrix between eight criteria. It was determined that in most cases the degree of correlation between the two criteria is low or weak, which can be characterized in the interval of correlation values of $(-0.4,0.4)$.

We found two medium to high correlation rates: Between the criteria, $X_{1}$ and $X_{3}$, and between the criteria, $X_{2}$ and $X_{8}$. In the cases of an increasing population density in the vicinity of station points $\left(X_{1}\right)$, the number of line crossings increases $\left(X_{3}\right)$. This results in greater possibilities for passengers crossing between lines and better access to PPT. Due to the importance of this, despite a high positive correlation, we decided to include this criterion in the line evaluation system. The relatively high degree of negative correlation between the $X_{8}$ and $X_{2}$ criteria is because of the prolongation of lines, 
which results in a higher value of the $X_{8}$ criterion and prolongs travel times, which, in turn, is reflected in a decrease in the criterion, $X_{2}$.

Table 3. Correlation matrix among the criteria in evaluating the results of the objective function.

\begin{tabular}{ccccccccc}
\hline Criteria & $\boldsymbol{X}_{1}$ & $\boldsymbol{X}_{2}$ & $\boldsymbol{X}_{3}$ & $\boldsymbol{X}_{4}$ & $\boldsymbol{X}_{5}$ & $\boldsymbol{X}_{6}$ & $\boldsymbol{X}_{7}$ & $\boldsymbol{X}_{8}$ \\
\hline$X_{1}$ & 1.00 & 0.24 & 0.87 & 0.04 & -0.15 & 0.17 & n.a. & -0.28 \\
$X_{2}$ & 0.24 & 1.00 & 0.06 & 0.34 & -0.04 & -0.04 & n.a. & -0.68 \\
$X_{3}$ & 0.87 & 0.06 & 1.00 & 0.01 & -0.25 & 0.36 & n.a. & -0.38 \\
$X_{4}$ & 0.04 & 0.34 & 0.01 & 1.00 & 0.00 & 0.23 & n.a. & -0.21 \\
$X_{5}$ & -0.15 & -0.04 & -0.25 & 0.00 & 1.00 & -0.24 & n.a. & 0.06 \\
$X_{6}$ & 0.17 & -0.04 & 0.36 & 0.23 & -0.24 & 1.00 & n.a. & -0.10 \\
$X_{7}$ & n.a. & n.a. & n.a. & n.a. & n.a. & n.a. & n.a. & n.a. \\
$X_{8}$ & -0.28 & -0.68 & -0.38 & -0.21 & 0.06 & -0.10 & n.a. & 1.00 \\
\hline
\end{tabular}

The calculated value of this function for each line in the selected pilot region shows a characteristic value for each line according to the PSO_PPT implementation parameters (column 2, Table 4). Comparative analyses between the lines considered indicate whether the results are meaningful and useful for further research. The results of the objective function model are important for the analysis by the PTA and represent the basis for taking measures to improve the value of this objective function for the observed lines. These values can be improved, for example, with a larger number of transit passengers on the line, with shorter travel times, with lower fares, with greater accuracy in the carrying out of services, etc. An important aspect is the analysis of which lines in the observed area achieve the best results and which ones are the worst.

Table 4. Comparison table of the results of the evaluation of the implementation of 28 lines in the observed pilot region, according to the objective function, variant 1, and variant 2 (marks in column 1 : A, B, C, D refer to the concession areas shown in Figure 5).

\begin{tabular}{|c|c|c|c|c|c|c|}
\hline $\begin{array}{l}\text { Line Number in } \\
\text { the Observed } \\
\text { Area }(A, B, C, D)\end{array}$ & $\begin{array}{c}\text { Calculated } \\
\text { Value of } \\
\text { Objective } \\
\text { Function (OF) }\end{array}$ & $\begin{array}{l}\text { The Order of } \\
\text { the Lines by } \\
\text { Decreasing } \\
\text { Values of (OF) }\end{array}$ & $\begin{array}{c}\text { Calculated } \\
\text { Optimization } \\
\text { Value (Y1) of } \\
\text { Variant } 1 \text { (V1) }\end{array}$ & $\begin{array}{l}\text { The Order of } \\
\text { the Lines by } \\
\text { Decreasing } \\
\text { Values (V1) }\end{array}$ & $\begin{array}{c}\text { Calculated } \\
\text { Optimization } \\
\text { Value (Y2) of } \\
\text { Variant } 2 \text { (V2) }\end{array}$ & $\begin{array}{l}\text { The Order of } \\
\text { the Lines by } \\
\text { Decreasing } \\
\text { Values (V2) }\end{array}$ \\
\hline APRA1915473 & 3.2 & 13 & 1.2903 & 22 & 1.4443 & 24 \\
\hline APRAA191552 & 3.05 & 18 & 1.9763 & 9 & 1.7248 & 20 \\
\hline APRA1916623 & 2.8 & 23 & 1.0906 & 27 & 1.3927 & 26 \\
\hline APRA1960507 & 4 & 6 & 2.1586 & 5 & 1.7884 & 16 \\
\hline APRA19703313 & 4.05 & 5 & 2.1758 & 4 & 1.7649 & 19 \\
\hline APRA1980081 & 3.3 & 11 & 1.2804 & 23 & 1.4111 & 25 \\
\hline APRA19805017 & 2.55 & 26 & 0.8925 & 28 & 1.5112 & 22 \\
\hline APRA19806119 & 4.29 & 3 & 1.9103 & 11 & 1.3447 & 28 \\
\hline BPRA1950145 & 3.2 & 14 & 1.6161 & 15 & 1.9405 & 9 \\
\hline BPRA1965182 & 2.48 & 27 & 1.3256 & 21 & 1.7065 & 21 \\
\hline BPRA1970168 & 3.5 & 8 & 1.8401 & 12 & 1.9405 & 10 \\
\hline BPRA198006 & 3.09 & 16 & 2.0458 & 7 & 1.9405 & 11 \\
\hline BPRA19806210 & 4.5 & 2 & 2.0144 & 8 & 1.9405 & 12 \\
\hline CPRA1916614 & 2.69 & 24 & 2.4103 & 2 & 2.1785 & 1 \\
\hline CPRA1980175 & 3.07 & 17 & 1.9564 & 10 & 1.5112 & 23 \\
\hline CPRA1980185 & 3.37 & 9 & 2.5705 & 1 & 1.9886 & 5 \\
\hline CPRA19805819 & 5.05 & 1 & 1.7244 & 14 & 1.9886 & 6 \\
\hline DPRA1912166 & 3.3 & 10 & 1.577 & 16 & 1.8046 & 14 \\
\hline DPRA198065241 & 2.8 & 22 & 1.5741 & 17 & 1.8046 & 15 \\
\hline
\end{tabular}




\subsubsection{Methodology for Setting up the Optimization Model}

After analyzing the results of the objective function model, the results of the optimization model were analyzed using linear regression methods and the least squares method. In this case, we used two versions of the models, which we named variant 1 (V1) and variant 2 (V2), as follows from Table 1 and Figure 2, taking into account the literature [29,30].

When setting the goal of this model (Section 2.2. in Figure 2), it was based on the experience of the existing operation of the PTA on the selected pilot area, which in the concession contracts for the implementation of PSO_PPT has set a certain cost price. The cost price can be determined for each line separately, with a requirement that the average price of all lines in the observed area is equal to the target cost price, as the price of a well-functioning company. The basis of the set model is a set of characteristic criteria, the values of which represent the quality of service performance measured on the observed line in the PSO_PPT system. In this way, the following vector record can be formed for each of the lines, $i \in\{1, \ldots 28\}$, and for each predictive criterion, $j \in\{1, \ldots 6\}$ :

$$
\begin{gathered}
\boldsymbol{X}_{j}=\left[\begin{array}{c}
x_{1 j} \\
\vdots \\
x_{m j}
\end{array}\right], \\
\boldsymbol{X}=\left[\begin{array}{lll}
\boldsymbol{X}_{\mathbf{1}} & \cdots & \boldsymbol{X}_{n}
\end{array}\right]=\left[\begin{array}{ccc}
x_{11} & \cdots & x_{1 n} \\
\vdots & \ddots & \vdots \\
x_{m 1} & \cdots & x_{m n}
\end{array}\right] .
\end{gathered}
$$

In a continuation of the research, we formed the following relation between the dependent variable $(\mathrm{Y})$ and the independent criteria $\left(X_{i}\right)$ :

$$
Y=\beta X+\varepsilon=\beta_{1} X_{1}+\ldots+\beta_{n} X_{n}+\varepsilon .
$$

Since the PTA operator has a certain cost price for a typical well-functioning company in charging the costs of implementing PSO_PPT, this price represents the target cost price. In this way, we defined the following vector:

$$
\mathbf{Y}=C_{c} \mathbf{1}_{m}
$$

where $C_{c}$ is the target cost price, and $\mathbf{1}_{m}$ is a column vector with $\mathrm{m}$ elements that are all equal to 1 . $\boldsymbol{\beta}=\left[\beta_{1}, \beta_{2}, \ldots \beta_{n}\right]$ represents a vector of coefficients, $\beta$, that determines the size of the influence of each independent variable, that is, the criterion, on the dependent variable. For linear regression procedures, there is also an error, $\varepsilon=\left[\varepsilon_{1}, \varepsilon_{2}, \ldots \varepsilon_{n}\right]$, which represents a deviation from the precise connection between $\mathbf{X}$ and $\mathbf{Y}$. For the solution, we used the method of the ordinary least squares, which gave us the next solution:

$$
\hat{\boldsymbol{\beta}}=\left(\boldsymbol{X}^{\prime} \boldsymbol{X}\right)^{-\mathbf{1}}\left(\boldsymbol{X}^{\prime} \boldsymbol{Y}\right)
$$

The new calculation of the dependent variable is written in the following form:

$$
\mathbf{Y}=\hat{\beta} X+\varepsilon .
$$

The calculated deviation square gives us the following form, divided by the difference between the number of lines, $m$, and the number of criteria, $n$, to get an unbiased estimate [29]:

$$
s^{2}=\frac{\hat{\varepsilon}^{\prime} \hat{\varepsilon}}{m-n} .
$$


The standard error was calculated as

$$
\widehat{S E\left(\beta_{j}\right)}=\sqrt{s^{2}\left(\boldsymbol{X}^{\prime} \boldsymbol{X}\right)_{j j}^{-1}} .
$$

The probability, $p\left(\hat{\beta}_{j}\right)$, value was calculated from the following record:

$$
p\left(\hat{\beta}_{j}\right)=t_{v}^{-1}\left(\frac{\hat{\beta}_{j}}{\widehat{S E\left(\beta_{j}\right)}}\right) .
$$

In this case, $t_{v}^{-1}$ represents the probability density of the student's T distribution with $(v=m-n)$ degrees of freedom, which was calculated as the difference between the number of lines in the observed area, $m$, and the number of criteria, $n$. The goal was set that the coefficient $(\beta)$ must be different from (0) and that the confidence interval $(95 \%)$ is valid for such a claim. The following statements were used:

- If $\left(p\left(\hat{\beta}_{j}\right)<0.05\right)$, the coefficient $(\beta)$ is statistically significant and was used in the final model.

- If $\left(p\left(\hat{\beta}_{j}\right)>0.05\right)$, we concluded that the coefficient $(\beta)$ is not statistically significant and was excluded from the model.

In the described procedure, we obtained the cost price forecasts of a typically well-functioning company, but optimization had not yet been made so that the average of these cost prices approached the target cost price. The optimization processes were carried out in such a way that the obtained coefficients $(\hat{\boldsymbol{\beta}})$ were changed by the methods of least squares optimization with respect to $(\widetilde{\beta})$ :

$$
\min _{\widetilde{\beta}}\left((\hat{\beta}-\widetilde{\beta})^{\prime}(\hat{\beta}-\widetilde{\beta})\right) .
$$

With an additional constraint:

$$
\begin{gathered}
\bar{C}=C_{c}, \\
\bar{C}=\frac{\sum_{i} Y_{i} v_{i} d_{i}}{\sum_{i} v_{i} d_{i}} .
\end{gathered}
$$

\section{Results}

The results of the optimization methods refer to the 28 lines discussed in the selected pilot region and on the previous mathematical notation six criteria. The results consist of:

- Previous calculations of the objective function value.

- Calculation of values by the model of further optimizations according to variant 1 (V1).

- Calculation of values by the model of further optimizations according to variant 2 (V2).

Criteria 7 and 8 were excluded due to insufficient and unreliable input data needed for further statistical processing. Thus, in performing optimization methods according to variant 1 and variant 2 , in step 1, calculations of linear regression and optimization based on the entire set of input data were performed taking into account six criteria. Since one of the results of the model is an evaluation of the statistical significance of individual criteria, as follows from $\left(p\left(\hat{\beta}_{j}\right)<0.05\right)$, all statistically insignificant criteria were eliminated in step 2 . In this way, we re-evaluated and optimized calculations only on the selection of criteria, as shown in Tables 5 and 6 . In both tables, the probability values (Val. p) are given, from which the statistical significance of the coefficients $(\beta)$ can be read. 
Table 5. Optimization processes by variant 1.

\begin{tabular}{ccccccc}
\hline & $\boldsymbol{\beta}_{1}$ & $\boldsymbol{\beta}_{2}$ & $\boldsymbol{\beta}_{3}$ & $\boldsymbol{\beta}_{4}$ & $\boldsymbol{\beta}_{5}$ & $\boldsymbol{\beta}_{6}$ \\
\hline Yreg1 & -0.14437009 & 0.31518185 & 0.21859679 & 0.29762479 & 0.20312520 & 0.13422008 \\
Yop1 & -0.14677137 & 0.31302232 & 0.21640598 & 0.29597583 & 0.20075972 & 0.13299863 \\
Yreg2 & & 0.40048314 & & 0.37411746 & 0.18654925 & \\
Yop2 & & 0.40044901 & & 0.37409142 & 0.18651190 & \\
Val. p & & $7.79076 \mathrm{E}-07$ & & $7.93111 \mathrm{E}-06$ & 0.03311431 & \\
\hline
\end{tabular}

The equation for evaluating the implementation of lines according to variant 1 can be written in the following form:

$$
C_{i}(\mathrm{~V} 1)=Y_{i}=0.40044901 x_{i 2}+0.37409142 x_{i 4}+0.18651190 x_{i 5}
$$

Table 6. Optimization processes by variant 2 .

\begin{tabular}{ccccccc}
\hline & $\boldsymbol{\beta}_{1}$ & $\boldsymbol{\beta}_{2}$ & $\boldsymbol{\beta}_{3}$ & $\boldsymbol{\beta}_{4}$ & $\boldsymbol{\beta}_{5}$ & $\boldsymbol{\beta}_{6}$ \\
\hline Yreg1 & -0.11023311 & 0.01148910 & 0.08209423 & 0.23582945 & 0.06569623 & -0.01334254 \\
Yop1 & -0.110397546 & 0.011333194 & 0.081944232 & 0.235292571 & 0.065534312 & -0.013426174 \\
Yreg2 & & & & 0.24283535 & & \\
Yop2 & & & & 0.24534751 & & \\
Val. p & & & & 0.00707572 & & \\
\hline
\end{tabular}

The equation for evaluating the implementation of lines according to variant 2 can be written in the following form:

$$
C_{i}(\mathrm{~V} 2)=Y_{i}=0.24534751 x_{i 4}
$$

Figure 6 shows a graphical representation of the results as follows from Table 1. From the graphs showing the values of functions, the largest range of values is observed in the objective function graph, followed by the optimization according to variant 1 and then by variant 2 . The results represent the basis for further analyses.

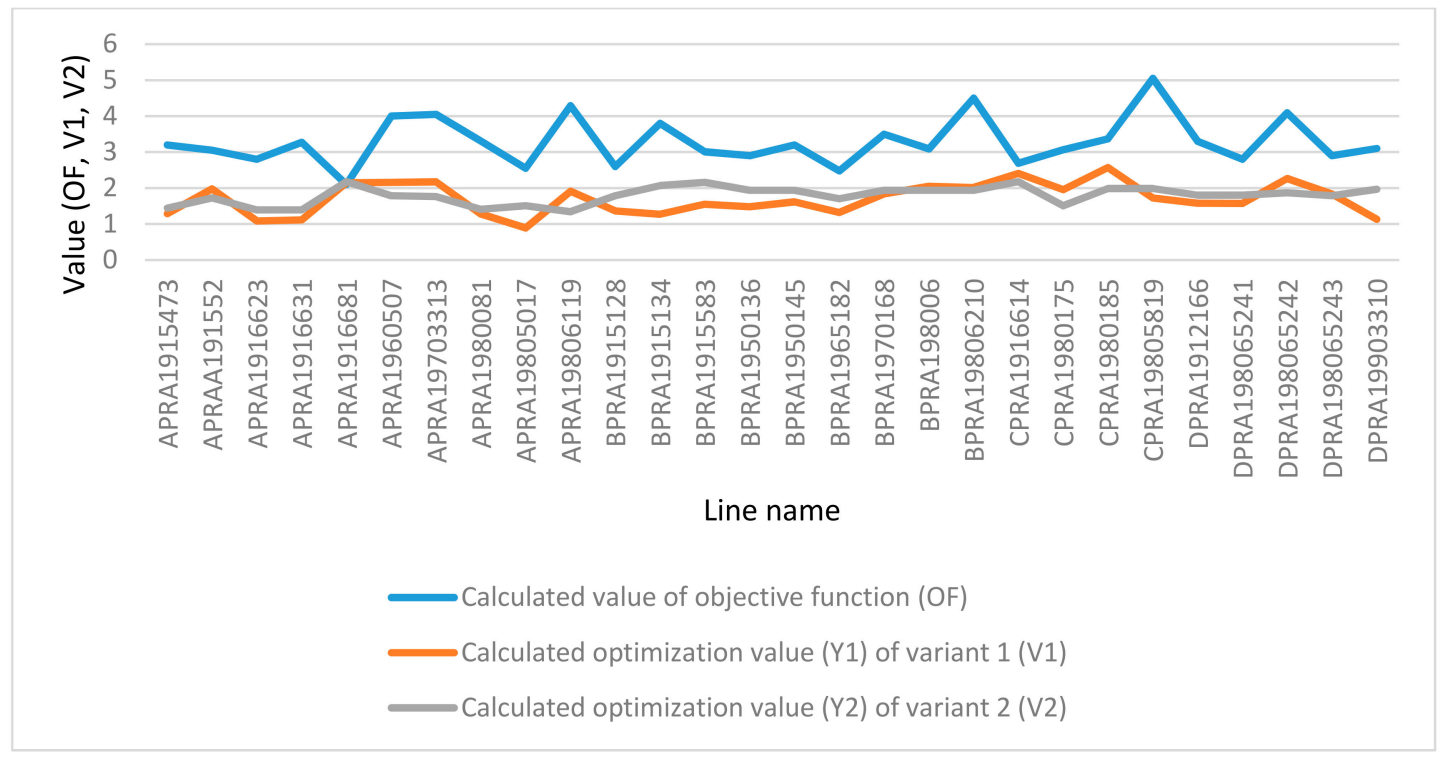

Figure 6. Calculated values $(Y)$ by three methods for each line 
Figure 7 shows the measured values of the functions on 28 lines by the three shown models according to the criteria records as follows from Table 1 . For the calculated values using the objective function model, eight criteria were used, and three criteria were used in the model V1; the model V2 used only 1 criterion as follows from Tables 5 and 6 . The graph shows the range of values of the results that is considerably higher in the objective function than in the V1 and V2 models. The graph also shows comparisons of the achieved value of the functions using the optimization models, V1 and V2, after the ranking from the lowest to the highest value by the objective function model.

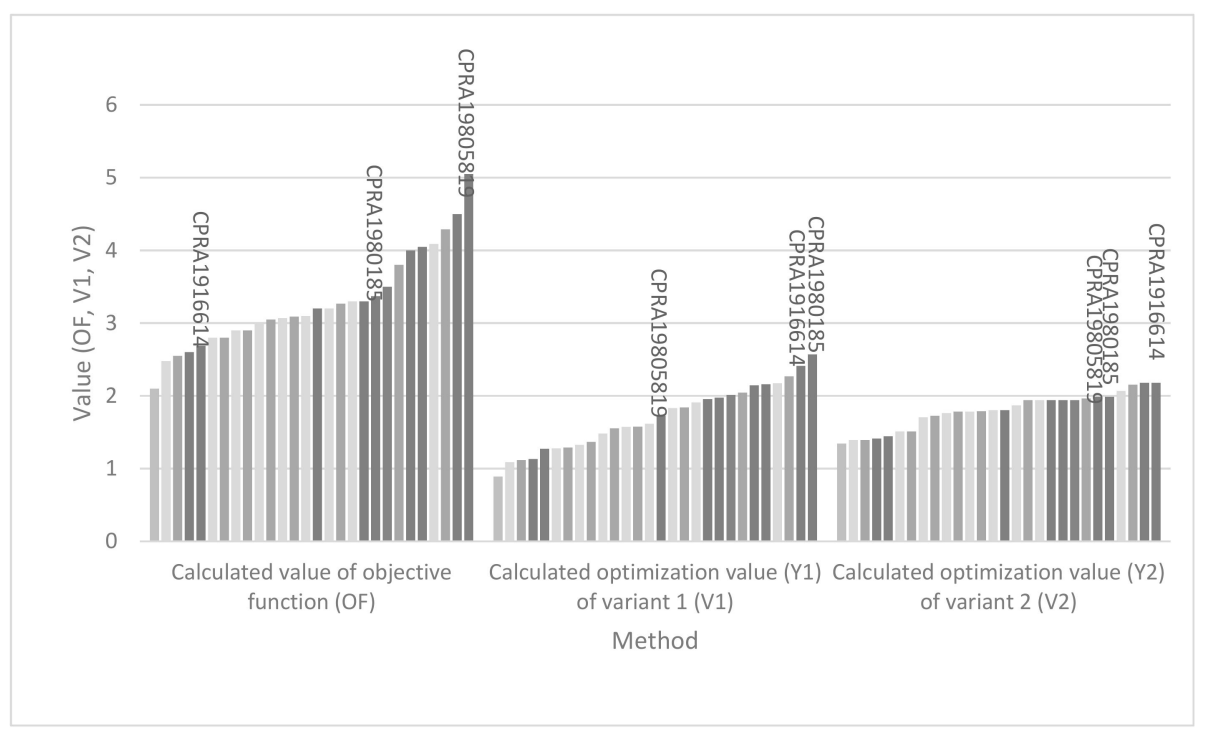

Figure 7. The value of functions (OF, V1, V2) according to the classification of lines from the minimum value to the maximum value by the model: objective function (OF), variant 1 (V1), and variant 2 (V2) by marking the position of the lines that reach the highest values in a particular model.

\section{Discussion}

The purpose of these surveys was to establish a model that will give the PTA the baseline data for evaluating the implementation of lines. With the current management of PSO_PPT throughout the area, as shown in Figure 4, it has been found that for the efficient management and allocation of public funds, it is necessary to prepare a model that will serve to evaluate the implementation of public passenger transport. It was established that without such a model, or one that is similar, the PTA pays compensation and subsidies to a transport operator without the possibility of checking the effectiveness of the performance of these services in advance. Setting up such a model is essential because the needs of the population and passengers are changing, and the growing demands for sustainable mobility are becoming increasingly important. In this way, we can make quicker adjustments to such changes. As the first stage of such analyses, we used the objective function model, because it offers us broad possibilities for setting criteria from the collected input data. It is crucial that we do not limit ourselves with statistical reliability at this stage, which is then subject to further optimization methods. In the case of the incorporation of such a model into the process (Figure 1), we can also add new criteria, for example, that serve to evaluate the financial uncertainty regarding the amount of subsidies and compensation payments.

Concerning optimization models, we can conclude that the model of further optimizations according to the variant 1 (V1) used is the best one for the following reasons:

- The obtained results show a sufficiently high statistical significance.

- Key criteria are taken into account, in which the selected contractor (transport operator) has the largest influence on the services of PSO_PPT: "Affordability", "Travel times", and "The rate of use of public passenger traffic." 
- There is a relatively large range between the highest and the lowest value of the parameter $(Y)$ according to this model, which allowed us to analyze and compare values between lines

The results of the research by the three models showed that there are lines that show the best results and have the highest values of functions across all three methods in the concession area (C). Lines that show the worst results, where the values of functions in all three cases were the lowest, lie in the concession area (A). Such results confirm the correctness of the design of concession areas relative to migration flows, as shown in Figure 5.

Each migration flow has its own characteristics that relate to the population density, travel time, line lengths, affordability, the degree of use of public passenger transport, and other factors. In this way, we can compare the results at the level of the concession areas, and in the next phase, at the level of lines within the concession areas. As an example, we indicate the line, APRA19703313, which occupies fifth place according to the criterion objective function, fourth place according to model V1, and 19th place according to model V2. This line shows the highest value of the criterion $\left(X_{5}\right)$ among all 28 lines, that is, "The rate of use of public passenger transport". This means that this line is the most effective in terms of population density, in proportion to the share of passengers using public passenger transport in the area of line implementation. The characteristic of all three models is that the higher the value of the criteria, the greater the functional values. This also follows from the records, both for model V1 and for model V2, for which all the coefficients $(\beta)$ having a negative sign were excluded. Therefore, the definition of criterion ranking is very important. With the objective function model, this was achieved by selecting correction factors and weights, and in further optimization models, by determining sufficient statistical reliability. Therefore, it is also important to determine whether we are interested in optimizing lines from the point of view of the PTA or from the point of view of passengers or transport operators (carriers).

The difference in function values for all these methods is based on the number of criteria considered: Eight criteria were taken into account in the objective function model, three criteria were considered in model V1, and only one criterion was taken into account in the V2 model. It is also a fact that the V1 and V2 model account for $95 \%$ of the statistical reliability, while only the correlation between the criteria was checked for the objective function model. The objective function model is appropriate in view of the fact that it takes into account a wide range of criteria, which can be further weighted. The other two models take into account statistical calculations and data processing, which was demonstrated by the elimination of criteria 7 and 8.

In the case of implemented optimizations, we proceeded from the target cost price of a well-functioning company, as follows from the concession contracts between the PTA and contractors. In the case of obtaining a different target cost price for another concession area, the entire optimization process needs to be repeated. In such cases, it is not possible to directly input the input data into Equation (14). An essential feature of the performed optimizations according to model V1 and V2 is that all coefficients $(\beta)$ have positive values, which means that all criteria lead to a higher final estimate of line values.

There are also limits to the transmission of the surveys presented to wider areas or to other public passenger transport management systems. The research presented in this article relates to the acquisition of data on weekdays and on a typical school day. It does not cover data on Saturdays, Sundays or during holidays. The restriction also applies to the size of the concession area. For the wider applicability of these surveys, we propose to extend the pilot area and a wider range of data capturing. In the case of additional data obtained or the need to evaluate the lines with additional criteria, the research or the methodology presented can be expanded. The next limit is the characteristic pilot area. Even though we wanted to capture the widest variety of lines with the 28 lines shown, there are still limitations. An example of this is the area of high-speed bus lines, which take place between major urban centers, mostly on motorways. For such special categories of lines, completely new research should be carried out. Otherwise, we believe that the research approach described and the methodology presented as a system are useful. 


\section{Conclusions}

When implementing the PSO_PPT management, it was found that the competent PTA has not yet developed an appropriate tool for evaluating the results of the implementation of the lines as described in Figure 1. Therefore, research was conducted according to the methodology shown in Figure 2.

This paper presents the methodology for the production of such a tool through the three mathematical models described. The models offer the option of evaluating the implementation of lines by showing the calculated values of the implementation of lines based on the input parameters. By comparing the results between the lines, we determined which lines achieve high values of functions and which achieve the lower ones. In subsequent analyses, we determined the reasons for such deviations arising from the input parameters in the model. In the analyses of the three models used, we found that the objective function had the largest range of values (2.1-5.05), model V1 had the range of values (0.89-2.57), and the V2 method (1.34-2.18). Comparative analyses of the results showed that it is reasonable to focus on three criteria, which have the greatest impact on the value of individual functions.

Applicable research values of this paper are intended for the management of PPT, which is the responsibility of the PTA. Here, we come to the following conclusions:

- The criterion of "travel times" was crucial in the evaluation. Therefore, in the case of objective function, a weight ratio (0.15) was added. Even with the V1 model, the coefficient, $\beta$, was the largest $\left(\beta_{2}=0.40\right)$, which also means the greatest impact. In order to achieve the best possible results for this criterion, it is important that travel times in PSO_PPT are as short as possible or as comparable as possible with the times of driving personal cars. A competent PTA can achieve this through the introduction of fast lines and itineraries in which there is minimal congestion. By identifying the travel habits of passengers and researching the origin-destination travel trips matrix, a competent PTA can optimally determine the itineraries of lines and departure times, thereby optimizing travel times.

- The next important criterion, which significantly affects the value of the implementation of lines, is price affordability. In this case, the added value of the weighting method (0.15) was added to the method of objective function, while the value of the coefficient $(\beta)$ was somewhat lower in the V1 model $\left(\beta_{4}=0.37\right)$, but still had a considerable influence. According to the V2 model, the coefficient $(\beta)$ was $\left(\beta_{4}=0.25\right)$. A competent PTA can significantly contribute to the greater use of PSO_PPT by lowering fares. The PTA should, in light of the available public funding, determine the optimal amount of ticket subsidies. The aim is to keep the fare as low as possible and to attract as many passengers as possible. A larger number of passengers also means more total revenues.

- For the criterion of the rate of use of PSO_PPT, the maximum value of the weight (0.2) was added for the objective function model, although the coefficient $(\beta)$ for the V1 method was lower than the two aforementioned $\left(\beta_{5}=0.19\right)$. We estimated that this criterion is one of the most important regarding the implementation of PSO_PPT. The values of this criterion can be increased by adjusting PSO_PPT to the needs of passengers, such as: Greater number of departures, introduction of interval timetables, introduction of fast lines, higher quality of services, etc.

- The results of the presented research have shown that we can describe the implementation of lines in the PSO_PPT system with different criteria. In the case of the described research, eight different criteria were used, among which there was a certain degree of connection and dependence. Therefore, a tool was developed that enables calculations by three different models according to the calculated degree of relevance of the individual criteria. After the comparative analyzes, we used the model to achieve the greatest effects for increasing the performance of the lines.

In order to use the results of these surveys throughout the entire PTA region, that is, the Republic of Slovenia, comparative analyses should be carried out in other characteristic areas. These are the areas of the implementation of bus routes as high-speed lines or lines running in concentrated traffic in combination with urban and suburban transport. Also, from the standpoint of sustainable mobility and 
the use of public passenger transport, we propose to continue the research on the further optimization of PSO_PPT implementation in relation to available public funds. In parallel, carrying out studies that show the most suitable sustainable alternative forms of propulsion technology vehicles in the public passenger transport system is recommended. This is based on the assumptions that we have data on the geographical and traffic characteristics of the concession area as well as the predetermined times of departures, population density, potential number of passengers, duration of journeys, distance traveled, and other relevant factors.

Author Contributions: J.B. prepared the initial research concept, lead the data acquisition process, prepared the infrastructure data and wrote the initial version of the manuscript. K.Z. provided the mathematical notation of the models V1 and V2 and developed the software tools for calculations, S.Z. reviewed the data and the methodology. M.A. led the research and contributed to data collection and processing, and writing the manuscript. All the authors have jointly revised the manuscript, and prepared the graphical material.

Funding: The work presented in this article was partly funded by the Slovenian Research Agency as part of the "Modelling in technics and medicine" (code P2-0109) research program.

Acknowledgments: The authors would like to thank the concessionaire Arriva Alpetour, d.o.o., 4000 Kranj, Slovenia, for providing the necessary pilot area data, which were used in the research.

Conflicts of Interest: The authors declare no conflict of interest. The funders had no role in the design of the study; in the collection, analyses, or interpretation of data; in the writing of the manuscript, or in the decision to publish the results.

\section{References}

1. EU Regulation. Regulation (EC) No 1370/2007 of the European Parliament and of the Council of 23 October 2007 on Public Passenger Transport Services by Rail and by Road and Repealing Council Regulations (EEC) No 1191/69 and 1107/70, OJL 315, 3.12.2007. pp. 1-13. Available online: http://data.europa.eu/eli/reg/2007/ 1370/oj (accessed on 30 March 2018).

2. Transport in the European Union, Current Trends and Issues. In Mobility and Transport; European Commission, Directorate-General Mobility and Transport: Brussels, Belgium, April 2018.

3. Brunagel, M.; Gohel, N.; Castella, C.; Hamrouni, A.F.; Protard, L.; Mocci, G. Exploratory Study on passenger rights in the multimodal context. In Draft Executive Summary, Study Contract No. MOVE/B5/SER/2016-77/SI2.760997; European Commission, Directorate-General for Mobility and Transport, European Commission: Brussels, Belgium, February 2019.

4. Velde, D.; Veeneman, W.; Schipholt, L.L. Competitive tendering in The Netherlands: Central planning vs. Functional specifications. Transp. Res. Part A 2008, 42, 1152-1162. [CrossRef]

5. Mouwen, A.; Ommeren, J. The effect of contract renewal and competitive tendering on public transport costs, subsidies and ridership. Transp. Res. Part A 2016, 87, 78-89. [CrossRef]

6. Farsi, M.; Fetz, A.; Filippini, M. Economies of Scale and Scope in Local Public Transportation. J. Transp. Econ. Policy 2007, 41, 345-361.

7. European Commission, Energy, Climate Change, Environment, Climate Action. Available online: https: //ec.europa.eu/clima/policies/transport_en (accessed on 30 March 2018).

8. Communication from the Commission to the European Parliament, the Council, the European Economic and Social Committee and the Committee of the Regions-\{SWD(2016) 244 final\} (2016). In A European Strategy for Low-Emission Mobility; European Commission: Brussels, Belgium, 2016.

9. Lopez, C.; Ruiz-Benitez, R.; Vargas-Machuca, C. On the Environmental and Social Sustainability of Technological Innovations in Urban Transport: The EU Case. Sustainability 2019, 11, 1413. [CrossRef]

10. Blaż, J.; Hočevar, M. Changing the management of public passenger transport in Slovenia on the basis of Austrian experience. Uprava Int. Sci. J. Theory Pract. 2008, 2, 105-121.

11. Ibarra-Rojas, O.J.; Delgado, F.; Giesen, R.; Munoz, J.C. Planning, operation, and control of bus transport system: A literature review. Transp. Res. Part B 2015, 77, 38-75. [CrossRef]

12. Jia, G.-L.; Ma, R.-G.; Hu, Z.-H. Urban Transit Network Properties evaluation and Optimization Based on Complex Network Theory. Sustainability 2019, 11, 2007. [CrossRef]

13. Attard, M. Reforming the urban public transport system in Malta: Approach and acceptance. Transp. Res. Part A 2012, 46, 981-992. [CrossRef] 
14. Costa, A.; Fernandes, R. Urban public transport in Europe: Technology diffusion and market organisation. Transp. Res. Part A 2012, 46, 269-284. [CrossRef]

15. Chowdhury, S.; Ceder, A.; Schwalger, B. The effects of travel time and cost savings on commuters' decision to travel on public transport routes involving transfers. J. Transp. Geogr. 2015, 43, 151-159. [CrossRef]

16. White, P. Public transport, Its Planning, Management and Operation, 5th ed.; Routledge: London, UK; New York, NY, USA, 2009.

17. Ambrož, M.; Korinšek, J.; Blaž, J.; Prebil, I. Integral management of public transport. In Proceedings of the 6th European Transport Research Conference Moving forward (TRA), Warsaw, Poland, 18-21 April 2016. [CrossRef]

18. Republika Slovenija, Statistični Urad (SURS). Available online: http://www.stat.si/statweb/ (accessed on 18 July 2017).

19. Korinšek, J.; Tekavčič, M.; Lavrih, N.; Ambrož, M.; Prebil, I. Creating a Software Solution for Connecting the Infrastructure and Economic-Financial Part of the Public Passenger Report; Final Report; University of Ljubljana, Faculty of Mechanical Engineering: Ljubljana, Slovenia, 2010.

20. Četrta Pot Application. Available online: http://www.e-karta.si/software/ (accessed on 23 November 2016).

21. I-Plus Application. Available online: http://www.iplus.si/?portfolio=ipotnik/ (accessed on 8 November 2015).

22. Ambrož, M.; Korinšek, J.; Prebil, I.; Blaž, J. Information system for public transport management. In Sustainable Transport and Mobility, Proceedings of the 17th International Symposium on Electronics in Traffic, ISEP, Ljubljana, Slovenia, 26 March 2009; University of Ljubljana, Faculty of Mechanical Engineering: Ljubljana, Slovenia, 2009.

23. Zou, W.; Yu, M.; Mizokami, S. Mechanism Design for an Incentive Subsidy Scheme for Bus Transport. Sustainability 2019, 11, 1740. [CrossRef]

24. Hawas, Y.E. Simulation-Based regression Models to Estimate Bus Routes and network Travel Times. J. Public Transp. 2013, 16, 107-130. [CrossRef]

25. Rohani, M.M.; Wijeyesekera, D.C.; Karim, A.T.A. Bus Operation, Quality Service and the Role of Bus Provider and Driver. Procedia Eng. 2013, 53, 167-178. [CrossRef]

26. Parbo, J.; Nielsen, O.A.; Prato, C.G. User perspectives in public transport timetable optimization. Transp. Res. Part C 2014, 48, 269-284. [CrossRef]

27. Stankovič, M.; Gladović, P.; Popovič, V.; Lukovac, V. Selection Criteria and Assessment of the Impact of Traffic Accessibility on the Development of Suburbs. Sustainability 2018, 10, 1977. [CrossRef]

28. Zorić, J.; Hočevar, M.; Jaklič, M.; Lep, M.; Gabrovec, M.; Pustovrh, A.; Kotar, M. Izdelava Ekonometričnega Modela Zadoločanje cen Vozovnic v Javnem Potniškem Prometu = Creating an Econometric Model for Determining Ticket Prices in Public Passenger Transport, Final Report for the Ministry of Infrastructure; University of Ljubljana, Faculty of Economic: Ljubljana, Slovenia, 2011; (In Slovenian). Available online: http://www.mzi.gov.si/fileadmin/mzi.gov.si/pageuploads/Trajnostna_mobilnost/Zbirno_porocilo_ o_izvajanju_GJS_JPP/Koncno_porocilo_Ekonometricne_analize_povprasevanja_po_JPP.PDF (accessed on 25 March 2019).

29. Green, W.H. Econometric Analyses, 5th ed.; Pearson Education Inc.: Upper Saddle River, NJ, USA, 2003; ISBN 0-13-066189-9.

30. Rice, J.A. Mathematical Statistics and Data Analyses, 3rd ed.; Thomson Higher Education: Belmont, CA, USA, 2007; ISBN 0-534-39942-8.

(C) 2019 by the authors. Licensee MDPI, Basel, Switzerland. This article is an open access article distributed under the terms and conditions of the Creative Commons Attribution (CC BY) license (http://creativecommons.org/licenses/by/4.0/). 